\title{
Kebidanan komplementer: Pengurangan nyeri persalinan dengan latihan birth ball
}

\author{
Noviyanti $^{1 *}$, Nurdahliana ${ }^{1}$, Fitri Munadya $^{2}$, Gustiana $^{1}$ \\ 1Politeknik Kesehatan Kemenkes Aceh, Jurusan Kebidanan. *Email: noviyantiaceh@gmail.com \\ 2Bidan Praktek Mandiri Erni Munir, Banda Aceh
}

Abstract

Advantage of birth ball exercises on labour pain management

\begin{abstract}
Background: Maternal Mortality Rate (MMR) in Indonesia is still high. 2015 Census Survey, MMR ranged from 305 / 100,000 live births. The MMR in Banda Aceh in 2016 was 37 per 100,000 live births. Pain during labour arises as a result of physical and psychological reflexes of the mother. Emotional tension due to anxiety will worsen the perception of pain felt by the mother during labour. Pain that occurs during labour requires proper pain management and this should be a concern for women, families and health workers. Pain labour during the first stage is severe pain that the mother feels in labor for a longer time. Non-pharmacological (Complementary) methods are proven to reduce labor pain, one of which is Birth Ball.
\end{abstract}

Purpose: To analyze the effectiveness of birth ball exercises on labour pain management

Method: An experimental study with a Pre and Post-Test Control Group Design approach. The population was primigravida first stage active mothers with a sample of 15 participants. The study was conducted at clinic of Midwife Practices in Banda Aceh City. The instrument used in this study was an observation sheet about the intensity of labor pain using the Faces Pain Rating Scale scale.

Results: Statistical tests were performed using the Wilcoxon Test and showed that the $p$ value $(0.001<0.05)$ so it can be concluded that there was a significant difference in the intensity of labour pain before and after Birth Ball exercises.

Conclusion: Birth ball exercises is one of the complementary midwifery care which can be implementation easily, cheaply, simply, effectively, and without adverse effects. Birth ball exercises had a significantly reduce labour pain in primigravida mother stage I.

\section{Keywords: Advantage; Birth ball exercises; Labour pain; Management}

Pendahuluan: Angka Kematian Ibu (AKI) di Indonesia masih tinggi. Survei Angka Sensus (Supas) tahun 2015, AKI berkisar 305/100.000 kelahiran hidup. AKI di Kota Banda Aceh pada tahun 2016 adalah 37 per 100.000 kelahiran hidup. Nyeri saat persalinan timbul sebagai akibat reflek fisik dan psikis ibu. Ketegangan emosi akibat rasa cemas akan memperburuk persepsi nyeri yang dirasakan oleh ibu saat melahirkan. Nyeri yang timbul saat persalinan, memerlukan manajemen pengelolaan nyeri yang tepat dan ini hendaknya menjadi perhatian bagi wanita, keluarga dan petugas kesehatan. Nyeri persallinan saat kala I merupakan nyeri berat yang dirasakan ibu bersalin dalam waktu yang lebih lama. Metode non farmakologis (Komplementer) terbukti dapat mengurangi nyeri persalinan salah satunya latihan Birth Ball.

Tujuan : Menganalisis efektifitas latihan birth ball pada ibu bersalin kala I terhadap penurunan nyeri persalinan di Praktek Mandiri Bidan (PMB) "EM" di Kota Bada Aceh

Metode : Penelitian eksperimental dengan pendekatan Pre and Post-Test Control Group Design. Populasinya ibu bersalin primigravida kala I fase aktif dengan jumlah sampel 15 partisipan. Penelitian di lakukan di Praktek Bidan Mandiri (PMB) "EM" di Kota Banda Aceh. Instrumen yang digunakan dalam penelitian ini adalah lembar observasi tentang intensitas nyeri persalinan dengan menggunakan skala Faces Pain Rating Scale.

Hasil : Uji statistik dilakukuan dengan menggunakan Uji Wilcoxon didapatkan nilai $p$-value $(0,001<0,05)$ jadi dapat disimpulkan bahwa terdapat perbedaan yang bermakna pada intensitas nyeri persalinan sebelum dan sesudah diberikan latihan Birth Ball.

Simpulan : Latihan Birth Ball adalah salah satu asuhan kebidanan komplementer yang dapat diberikan secara mudah, murah, simple, efektif, dan tanpa efek yang merugikan. Birth Ball secara signifikan dapat menurunkan nyeri persalinan pada ibu primigravida kala I.

Kata Kunci : Persalinan; Nyeri persalinan; Latihan birth ball. 


\section{PENDAHULUAN}

Sebanyak 810 ibu setiap hari meninggal akibat penyakit/komplikasi terkait kehamilan dan persalinan pada tahun 2017 dan angka Kematian Ibu (AKI) masih tinggi di Indonesia. Diperkirakan AKI 305/100.000 kelahiran hidup tahun 2015 . Tahun 2012 AKI yaitu 359/100.000 kelahiran hidup. Target pemerintah tahun 2024 AKI berjumlah 232/100.000 kelahiran hidup. Penyebab kematian ibu antara lain, hipertensi sebanyak $33,07 \%$, perdarahan obstetrik $27.03 \%$, komplikasi non obstetric $15.7 \%$, komplikasi obstetric lainnya $12.04 \%$, infeksi pada kehamilan $6.06 \%$ dan penyebab lainnya $4.81 \%$ (Kementerian Kesehatan Republik Indonesia, 2018; World Health Organization, 2019).

Jumlah kematian ibu di Provinsi Aceh tahun 2015 adalah 134 kematian ibu. Tahun 2016 mengalami peningkatan angka kematian ibu sebanyak 167 dan menurun jumlah kematian ibu menjadi 143 pada tahun 2017. Angka Kematian Ibu di Kota Banda Aceh pada tahun 2016 adalah 37 per 100.000 kelahiran hidup terjadi penurunan dibandingkan dengan Tahun 2015 sebesar 114 per 100.000 kelahiran hidup, tahun 2014 sebesar 92 Per 100.000 kelahiran hidup Tahun 2013 sebesar 119 per 100.000 kelahiran hidup dan tahun 2012 sebesar 20 per 100.000 kelahiran hidup (Dinas Kesehatan Provinsi Aceh, 2018). Kematian ibu merupakan akibat dari komplikasi kebidanan yang tidak di tangani secara tepat. $15 \%$ kehamilan/persalinan mengalami komplikasi (Achadi, 2019).

Persalinan merupakan hal yang fisiologis. Nyeri saat persalinan timbul sebagai akibat reflek fisik dan psikis ibu. Ketegangan emosi akibat rasa cemas akan memperburuk persepsi nyeri yang dirasakan oleh ibu saat melahirkan. Nyeri yang timbul saat persalinan, memerlukan manajemen pengelolaan nyeri yang tepat dan ini hendaknya menjadi perhatian bagi wanita, keluarga dan petugas kesehatan (Kartini, 2017). Kejadian nyeri pada ibu bersalin, $15 \%$ mengalami nyeri ringan, $35 \%$ dengan nyeri sedang, $30 \%$ dengan nyeri hebat dan 20\% persalinan disertai nyeri sangat hebat (Rejeki, 2014). 67\% ibu merasa khawatir terhadap nyeri pada saat persalinan, oleh karena itu, perlu dipertimbangkan tentang bagaimana cara mengatasi nyeri tersebut. Penelitian di Amerika Serikat sekitar $70 \%$ sampai $80 \%$ ibu yang melahirkan mengharapkan persalinan berlangsung tanpa merasakan nyeri, saat ini $20 \%$ hingga $50 \%$ persalinan dirumah sakit swasta di Indonesia dilakukan dengan operasi Caesar. Trend pada saat ini kecenderungan para ibu memilih persalinan secara operasi sectio caesarea untuk menghindari rasa nyeri saat melahirkan normal (Halimatussakdiah, 2017). Kondisi psikologis ibu seperti ketakutan, ketegangan dan ansietas membuat ibu menjadi lebih nyeri (Kennedy, Ruth, \& Martin, 2019).

Nyeri persallinan saat kala I merupakan nyeri berat yang dirasakan ibu bersalin dalam waktu yang lebih lama. Jumlah ibu bersalin Primigravida yang mengalami nyeri berat sebanyak 46\%, 64\% mengalami nyeri sedang dan ringan, sedangkan pada multigravida sebanyak $37 \%$ ibu bersalin mengalami nyeri berat, dan $63 \%$ mengalami nyeri sedang dan ringan (Farida, 2016). Nyeri pada saat persalinan menyebabkan ibu sulit untuk beradaptasi sehingga menyebabkan tidak terkoordinasinya kontraksi uterus yang dapat mengakibatkan perpanjangan kala I persalinan dan keadaan janin akan terganggu. Untuk menghilangkan rasa nyeri dapat digunakan dengan metode farmakologis dan nonfarmakologis (terapi komplementer). Penanganan nyeri secara farmakologis masih banyak menimbulkan pertentangan karena pemberian obat selama proses persalinan akan memberikan efek negatif bagi janin maupun ibu (Kartini, 2017).

Metode non farmakologis (Komplementer) dapat digunakan oleh suluruh lapisan masyarakat secara murah, murah, simple, efektif, dan tanpa efek yang merugikan. Salah satu tehnik relaksasi dan tindakan nonfarmakologi dalam penanganan nyeri saat persalinan dengan menggunakan birth ball yang juga biasa dikenal dalam senam pilates sebagai filball, swiss ball, dan petzi ball, teknik pernapasan, pergerakan dan perubahan posisi, relaksasi, hidroterapi, terapi panas/dingin, musik, guided imagery, akupresur, aromaterapi merupakan beberapa teknik yang dapat meningkatkan kenyamanan ibu saat bersalin, sehingga efektif menurunkan nyeri pada saat persalinan (Fitriyani, 2018). Hasil penelitian sebelumnya terdapat perbedaan yang signifikan intensitas nyeri persalinan kala I fase aktif pada ibu primigravida yang dilakukan Birth Ball dengan yang tidak melakukan latihan Brith Ball. Latihan ini juga dapat membantu meningkatkan kemajuan 
persalinan Kala I Fase Aktif (Rohmah, 2017; Kartini, 2017).

Tujuan penelitian ini adalah untuk menganalisis efektifitas latihan birth ball pada ibu bersalin kala I terhadap penurunan nyeri persalinan di Praktek Mandiri Bidan (PMB) "EM" di Kota Bada Aceh. Manfaat penelitian yaitu latihan Birth Ball dapat dijadikan salah satu terapi komplementer dalam mengurangi nyeri persalinan.

\section{METODE PENELITIAN}

Penelitian eksperimental dengan pendekatan Pre and Post-Test Control Group Design. Populasinya ibu bersalin primigravida kala I fase aktif yang berusia 20-35 tahun yang tidak memiliki komplikasi pada ibu dan janin, dengan jumlah sampel 15 sebagai partisipan.

Penelitian di lakukan di Praktek Bidan Mandiri (PMB) "EM" di Kota Banda Aceh. Instrumen yang digunakan berupa lembar observasi tentang intensitas nyeri persalinan dengan menggunakan skala Faces Pain Rating
Scale, dengan intensitas 0 tidak ada rasa sakit, 1 sedikit menyakitkan, 2 lebih menyakitkan, 3 lebih menyakitkan lagi, 4 jauh lebih menyakitkan, 5 benar-benar menyakitkan.

Partisipan dilakukan latihan Birth Ball selama 30 menit persesi, latihan sebanyak 2 kali selama enam puluh menit pada kala I persalinan. Pada sesi pertama partisipan dianjurkan untuk duduk diatas Birth Ball dengan bimbingan oleh instruktur, kemudian diukur intensitas nyeri persalinan ibu lalu pasien istirahat selama 5 menit. Kemudian dilanjutkan pada sesi ke 2 ibu duduk diatas Birth Ball selama 30 menit lalu di ukur kembali intensitas nyeri persalinan. Observasi dimulai pada persalinan kala I fase aktif (pembukaan 4-7 cm), menganjurkan ibu untuk duduk diatas Birth Ball dengan gerakan mengayunkan dan menggoyangkan pinggul kedepan dan kebelakang sisi kanan, sisi kiri dan gerakan melingkar. Pengukuran dilakukan sebanyak 2 kali dengan melihat skala nyeri setelah 30 menit dan 60 menit latihan Birth Ball.

HASIL

Tabel 1. Karakteristik Responden $\mathrm{N}=15$

\begin{tabular}{lcc}
\hline Variabel & Frekuensi (f) & Persentase (\%) \\
& & \\
\hline Usia & 7 & 47 \\
$22-25$ tahun & 8 & 53 \\
$26-30$ tahun & & \\
& & 7 \\
Pendidikan & 1 & 53 \\
SMP & 8 & 40 \\
SMA & 6 & \\
Perguruan Tinggi & & 33 \\
& & 67 \\
Usia Kehamilan & 5 & \\
40 minggu & 10 & \\
\hline
\end{tabular}

Dari tabel 1 dapat diketahui bahwa mayoritas usia partisipan adalah 26-30 tahun sebanyak $53 \%$ berpendidikan SMA $53 \%$ dan usia kehamilan 40 minggu $67 \%$.

Tabel 2. Hasil Uji Normalitas Data

\begin{tabular}{cccccccc}
\hline Latihan Birth Ball & $\mathbf{n}$ & Mean & Standar Deviasi & Min & Max & Statistik & Sig \\
\hline Pre-Test & 15 & 2,6 & 0,507 & 2 & 3 & 0.630 & \multirow{2}{*}{0,000} \\
Post-Test & 15 & 1,7 & 0,516 & 1 & 2 & 0.643 & \\
\hline
\end{tabular}

Noviyanti ${ }^{1 *}$, Nurdahliana', Fitri Munadya ${ }^{2}$, Gustiana'

'Politeknik Kesehatan Kemenkes Aceh, Jurusan Kebidanan. *Email: noviyantiaceh@gmail.com

${ }^{2}$ Bidan Praktek Mandiri Erni Munir, Banda Aceh 
Berdasarkan tabel 2. Hasil uji normalitas menggunakan Uji Shapiro-Wilk didapatkan nilai sig lebih kecil dari nilai alpha $(0,000<0,005)$. Jadi dapat disimpulkan bahwa data berdistribusi tidak normal.

Tabel 3. Hasil Analisis Intensitas Nyeri Persalinan

\begin{tabular}{cccc}
\hline \multirow{2}{*}{ Intervensi } & \multicolumn{2}{c}{ Mean } & \multirow{2}{*}{ p-value } \\
\cline { 2 - 3 } & Pre-Test & Post-Test & \\
\hline Latihan Birth Ball & 2,6 & 1,7 & 0,001 \\
\hline
\end{tabular}

Berdasarkan tabel 3. Hasil uji statistik dilakukuan dengan menggunakan Uji Wilcoxon didapatkan nilai $p$ lebih kecil dari nilai alpha $(0,001<0,05)$ jadi dapat disimpulkan bahwa terdapat perbedaan yang bermakna pada intensitas nyeri persalinan sebelum dan sesudah diberikan latihan Birth Ball.

Hasil penelitian yang dipaparkan berdasarkan tabel 3 diatas dapat disimpulkan bahwa latihan Birth Ball pada ibu primigravida efektif dalam menurunkan nyeri persalinan pada Kala I. Hasil penelitian ini sesuai dengan penelitian sebelumnya di Yogyakarta yang menunjukkan hasil terdapat perbedaan rata - rata intensitas nyeri persalinan dengan skala lebih ringan dengan kelompok kontrol dengan nilai signifikan 0,019 yang artinya ada hubungan yang signifikan antara terapi Birth Ball dengan penurunan intensitas nyeri (Maryani, \& Estiwidani, 2016).

Penelitian sebelumnya mendapatkan hasil perbedaan nyeri persalinan sebelum dan sesudah pemberian birth ball (Fadmiyanor, Rahmi, \& Ayu, 2017; Hani, 2017). Latihan birth ball yang dilakukan ibu bersalin dengan cara duduk dengan santai dan bergoyang diatas bola, memeluk bola selama kontraksi memiliki manfaat membantu ibu dalam mengurangi rasa nyeri saat persalinan. Seorang ibu yang mampu melakukan relaksasi seirama dengan kontraksi uterus berlangsung maka ibu tersebut akan mengalami kenyamanan selama proses persalinan (Irawati, Susianti, \& Haryono, 2019).

Selama ibu menggunakan Birth Ball saat kontraksi ibu duduk senyaman mungkin dan bentuk bola yang dapat menyesuaikan dengan bentuk tubuh ibu membuat ibu lebih relaks dan ligament otot terutama di bagian panggul menjadi kendor dan menguranggi tekanan pada sendi sacriliaka, pembuluh darah sekitar uterus dan tekanan pada kandung kemih, punggung, pinggang, serta mengurangi tekanan pada perineum (Sutriningsih, Destri, \& Shaqinatunnissa, 2019). Beberapa hasil penelitian menguatkan dugaan dan pendapat yang menyatakan bahwa latihan birth ball meningkatkan intensitas nyeri persalinan Kala I Fase Laten (Dewi, Aryawan, Ariana, \& Nandarini, 2020).
Nyeri yang dirasakan ibu pada saat persalinan merupakan hal yang fisologis namun apabila nyeri persalinan dibiarkan saja maka akan berdampak kepada hal yang tidak diinginkan seperti kala I yang memanjang. Oleh karena itu birth ball merupakan salah satu cara nonfarmakologis untuk mengurangkan nyeri pada saat persalinan kala I. Hal ini sesuai dengan penelitian literatur tentang terapi non farmakologi efektif dapat mengurangi nyeri persalinan (Solehati, 2018). Latihan ini membuat ibu merasa nyaman dan lebih rilek. Selain itu, latihan birth ball juga bermanfaat untuk mempecepat pembukaan serviks, memperlebar diameter panggul serta mempercepat penurunan kepala janin. Latihan birth ball sebaiknya dilakukan sejak kehamilan trimester 3 (Sriwenda, \& Yulinda, 2017).

Latihan Birth Ball dapat meningkatkan efikasi diri dan mempercepat persalinan normal pada ibu primigravida. Latihan ini merangsang refleks postural dan menjaga otot-otot tulang belakang dalam keadaan baik (Tian, Kao, Lin, Chang, \& Gau, 2013). Hasil penelitian ini menguatkan dugaan dan pendapat bahwa ibu hamil yang memiliki efikasi tinggi memiliki nyeri yang lebih ringan. Intensitas nyeri persalinan sebelum dan setelah latihan birth ball memiliki pengaruh yang signifikan (Sari, 2019).

\section{SIMPULAN}

Penanganan nyeri persalinan dapat dilakukan secara farmakologis dan juga non farmakologis (komplementer). Asuhan kebidanan komplementer merupakan asuhan yang dapat diberikan secara mudah, murah, simple, efektif, dan tanpa efek yang merugikan. Salah satu nya yaitu dengan latihan Birth Ball. Latihan Bitth Ball pada ibu bersalin primigravida Kala I, secara signifikan dapat menurunkan nyeri persalinan. Hal ini karena membuat ibu nyaman, rileks dan mempercepat penurunan kepala janin. 


\section{DAFTAR PUSTAKA}

Achadi, E. L. (2019). Kematian Maternal dan Neonatal di Indonesia. Universitas Indonesia, Fakultas Kesehatan Masyarakat, Tangerang, Banten.

Dewi, P. I. S., Aryawan, K. Y., Ariana, P. A., \& Nandarini, N. A. P. E. (2020). Intensitas nyeri persalinan kala I fase laten pada ibu inpartu menggunakan birth ball exercise. Jurnal Keperawatan Silampari, 3(2), 456-465.

Dinas Kesehatan Provinsi Aceh. (2018). Profil Kesehatan Aceh Tahun 2017. Diakses dari : https://dinkes.acehprov.go.id/uploads/Profil_Din kes_Aceh_2017.pdf

Fadmiyanor, I., Rahmi, J., \& Ayu, M. P. (2017). Pengaruh pemberian metode birth ball terhadap intensitas nyeri persalinan kala 1 fase aktif di BPM Siti Julaeha. Jurnal Ibu Dan Anak, 5(2), 102-109.

Farida, S. (2016). Efektivitas Relaksasi Nafas dalam terhadap Nyeri Persalinan Kala I di BPM Fajar Endrowati Boyolali. Jurnal Maternity, 3(3).

Fitriyani, N. (2018). Penggunaan birth ball untuk mengurangi nyeri persalinan kala i di praktik mandiri bidan Aning Friyanti, AMD. Keb (Doctoral dissertation, STIKES Muhammadiyah Gombong).

Halimatussakdiah, H. (2017). Back-Effluerage Massage (BEM) terhadap Nyeri dan Tekanan Darah Ibu Bersalin Kala I. Jurnal Kesehatan, 8(1), 78-83.

Hani, U. (2017). Hubungan penggunaan tekhnik birthball dengan tingkat nyeri pada ibu bersalin kala I di BPM Umu Hani Yogyakarta Tahun 2015. Jurnal Keperawatan Intan Husada, 4(1).

Irawati, A., Susianti, S., \& Haryono, I. (2019). Mengurangi nyeri persalinan dengan teknik birthing ball. Jurnal Bidan Cerdas, 2(1), 15-22.
Kartini, F. (2017). Efektivitas latihan birth ball terhadap penurunan nyeri persalinan kala i fase aktif pada primigravida (Doctoral dissertation, Universitas Alma Alta).

Kementerian Kesehatan Republik Indonesia. (2018). Profil Kesehatan Indonesia 2017. Diakses dari https://www.kemkes.go.id/resources/download/ pusdatin/profil-kesehatan-indonesia/ProfilKesehatan-Indonesia-tahun-2017.pdf

Kennedy, B. B., Ruth, D. J., \& Martin, E. J. (2019). Modul manajemen intrapartum. EGC.

Maryani, T., \& Estiwidani, D. (2016). Terapi birth ball berpengaruh terhadap lama kala II dan intensitas nyeri persalinan pada ibu bersalin primigravida di RB Kasih lbu Yogyakarta. Jurnal Kesehatan Ibu Dan Anak, 10(2).

Rejeki, S. (2014). Tingkat nyeri dan prostaglandine2 (pg-e2) pada ibu inpartu kala I dengan tindakan counter-pressure. Jurnal Ners, 9(1), 111-117.

Rohmah, M. (2017). Penerapan teknik active birth menggunakan birth ball terhadap kemajuan persalinan kala i fase aktif pada ibu bersalin di BPM Wiwik Gunandari S. ST (Doctoral dissertation, STIKES Muhammadiyah Gombong).

Sari, W. I. P. E. (2019). The effect of pregnancy exercise use of birth ball on pain perceptions and self efficacy on primigravida during labor. Jurnal IImiah Bidan, 4(1).

Solehati, T. (2018). Terapi nonfarmakologi nyeri padapersalinan: Systematic review. Jurnal Keperawatan Muhammadiyah, 3(1).

Sriwenda, D., \& Yulinda, Y. (2017). Efektifitas latihan birth ball terhadap efikasi diri primipara dengan persalinan normal. Jurnal Ners dan Kebidanan Indonesia, 4(3), 141-147. 
Kebidanan komplementer: Pengurangan nyeri persalinan dengan latihan birth ball

Sutriningsih, S., Destri, Y., \& Shaqinatunissa, A. (2019). Pengaruh birth ball terhadap nyeri persalinan. Wellness and healthy magazine, 1(1), 125-132.

Tian, S. H., Kao, C. H., Lin, K. C., Chang, C. Y., \& Gau, M. L. (2013). Effects of birth ball exercises on labor pain and childbirth satisfaction. Journal of Nursing \& Healthcare Research, 9(1)
World Health Organization. (2019). Maternal Mortality. Diakses dari : https://www.who.int/news-room/factsheets/detail/maternal-mortality 